\title{
Chemo-immunotherapy improves long- term survival in a preclinical model of MMR-D-related cancer
}

\author{
Claudia Maletzki $^{1 *} \mathbb{D}$, Leonie Wiegele ${ }^{1}$, Ingy Nassar ${ }^{1}$, Jan Stenzel ${ }^{2}$ and Christian Junghanss ${ }^{1}$
}

\begin{abstract}
Background: Mismatch Repair Deficiency (MMR-D)-related tumors are highly immunogenic and constitute ideal vaccination targets. In a proof-of-concept study delayed tumorigenesis and prolonged survival has been shown in a clinically-relevant mouse model for MMR-D-related diseases (=MLH1 knock out mice). To refine this approach, vaccination was combined with immune modulatory low-dose chemotherapy to polarize immune regulatory subtypes.

Methods: Mice (prophylactic: 8-10 weeks; therapeutic: > 36 weeks) received a single injection of cyclophosphamide (CPX, $120 \mathrm{mg} / \mathrm{kg}$ bw, i.p.) or gemcitabine (GEM, $100 \mathrm{mg} / \mathrm{kg}$ bw, i.p.) prior to vaccination (lysate of a gastrointestinal tumor allograft, $10 \mathrm{mg} / \mathrm{kg}$ bw, $n=9$ mice/group). The vaccine was given repetitively ( $10 \mathrm{mg} / \mathrm{kg}$ bw, s.c., 4 x / once a week, followed by monthly boosts) until tumor formation or progression. Tumor growth ([ $\left.{ }^{18} \mathrm{~F}\right] \mathrm{FDG}$ PET/CT imaging) and immune responses were monitored (flow cytometry, IFNy ELISpot). The microenvironment was analyzed by immunofluorescence.
\end{abstract}

Results: Prophylactic application of GEM + lysate delayed tumorigenesis compared to lysate monotherapy and CPXpre-treatment (median time of onset: 53 vs. 47 vs. 48 weeks). 33\% of mice even remained tumor-free until the experimental endpoint (= 65 weeks). This was accompanied by long-term effect on cytokine plasma levels; splenic myeloid derived suppressor cells (MDSC) as well as regulatory T cell numbers. Assessment of tumor microenvironment from GEM + lysate treated mice revealed low numbers of MDSCs, but enhanced T cell infiltration, in some cases coexpressing PD-L1. Therapeutic chemo-immunotherapy (GEM + lysate) had minor impact on overall survival (median time: 12 (GEM + lysate) vs. 11.5 (lysate) vs. 3 weeks (control)), but induced complete remission in one case. Dendritic and $\mathrm{T}$ cell infiltrates increased in both treatment groups. Reactive T cells specifically recognized $\mathrm{MLH}^{-1-}$ tumor cells in IFNY ELISpot, but lacked response towards NK cell targets YAC-1.

Conclusions: Combined chemo-immunotherapy impairs tumor onset and growth likely attributable to modulation of immune responses. Depleting or 're-educating' immunosuppressive cell types, such as MDSC, may help moving a step closer to combat cancer.

Keywords: Tumor lysate, Gemcitabine, MMR deficiency, In vivo imaging, Tumor microenvironment

\footnotetext{
* Correspondence: claudia.maletzki@med.uni-rostock.de

${ }^{1}$ Department of Medicine, Clinic III - Hematology, Oncology, Palliative

Medicine, Rostock University Medical Center, Ernst-Heydemann-Str. 6, 18057

Rostock, Germany

Full list of author information is available at the end of the article
}

(c) The Author(s). 2019 Open Access This article is distributed under the terms of the Creative Commons Attribution 4.0 International License (http://creativecommons.org/licenses/by/4.0/), which permits unrestricted use, distribution, and reproduction in any medium, provided you give appropriate credit to the original author(s) and the source, provide a link to the Creative Commons license, and indicate if changes were made. The Creative Commons Public Domain Dedication waiver (http://creativecommons.org/publicdomain/zero/1.0/) applies to the data made available in this article, unless otherwise stated. 


\section{Background}

Cancer vaccines (autologous, peptide-based, viral vector, and dendritic cells) provide an excellent tool to restore or augment antitumoral immune responses. Such vaccines exhibit unique tumor cell specificity and the potential to persuade durable, long-lasting efficacy because of T-cell driven immunologic memory induction [1]. They can be either given in a preventive or therapeutic setting [2]. Since the introduction of the first personalized prostate cancer vaccine in 2010 (= sipuleucel-T), many other immunotherapeutic approaches, such as adoptive cell transfer and oncolytic viruses were developed and some of them are still under clinical investigation [2, 3]. Restoration of immune responses with immune-checkpoint inhibitors such as anti-PD-1, antiCTLA-4 and anti-PD-L1 is currently widely applied in the clinic and has shown remarkable success in the management of certain types of cancers [4-7]. However, recent studies describe intrinsic as well as acquired resistance mechanisms. Cancer vaccines may thus have a broader range of applications, not confined to a particular patient cohort and apart from this, with a better safety profile $[8,9]$. Neoadjuvant anti-tumor vaccination was even shown to improve post-surgical survival in an experimental mouse model [10].

Inactivation of the mismatch repair (MMR) system defines a molecular subtype with great potential to be targeted immunologically. The molecular fingerprint of resulting tumors is microsatellite instability (MSI) characterized by an outstandingly high mutation burden and an accordingly high abundance of frameshifted neo-epitopes on the tumor cells' surface [5, 11-13]. These neo-epitopes are unique to each individual patient, foreign to the immune system and represent ideal vaccination targets, without conferring risk to induce autoimmunity. Mutation-derived neoantigen cancer vaccines consequently entered clinical phases I/II (clinical trials.gov identifier: NCT01461148 \& NCT01885702).

Additionally to choosing the right target antigen(s), modulating the tumor microenvironment is crucial to counteract immune evasion [14]. Tumors promote infiltration of regulatory $\mathrm{T}$ cells (Treg), tumor-associated macrophages, and myeloid-derived suppressor cells (MDSCs). These cellular subtypes are considered to thwart the innate (dendritic cells (DC) and NK cells) and adaptive $\left(\mathrm{CD}^{+} \mathrm{T}\right.$ cells) arm of tumor immunosurveillance by secreting nitric oxide, reactive oxygen species and immunosuppressive cytokines such as IL-10 and TGF- $\beta$ [15]. They even contribute to resistance towards immune checkpoint inhibition [16]. Neutralizing the effect of immunosuppressive subpopulations yet preserving T-cell function seems thus reasonable to increase vaccine efficacy.

In a previous study, delayed tumorigenesis and prolonged survival after repetitive application of a cancer vaccine was described in a clinically-relevant mouse model for MMR-D-related diseases [17]. To refine this approach, vaccination was combined with single low-dose chemotherapy as precondition to polarize immunosuppressive cells and thus modulate the immune system. Pretreatment was either done with Cyclophosphamide (CPX) or Gemcitabine (GEM) followed by repetitive vaccination of $\mathrm{MLH}^{-/-}$mice. Applying this concept we aimed at restoration of immune responses to break intrinsic tolerance against self neo-antigens.

\section{Material and methods}

\section{Cell culture \& drug response analysis}

The $\mathrm{MLH}^{-/-}$cell lines were either established from gastrointestinal (cell lines: A7450 T1 M1 and 328 [18]) or lymphoid (cell line: 1351, origin: spleen; non-Hodgkin's lymphoma (CD4 ${ }^{+} \mathrm{CD} 8^{+} \mathrm{T}$-cell type) tumors. All cell lines were characterized (growth kinetic, phenotype) and successfully maintained in cell culture for $>30$ passages. For in vitro drug response analyses, passages between 15 and 20 were used. Cells were cultured in DMEM/Ham's F12 (Biochrom, Berlin, Germany) supplemented with $10 \%$ FCS (PAN-Biotech, Aidenbach, Germany) and 2 mM L-Glutamine (Biochrom) at $37^{\circ} \mathrm{C}, 5 \% \mathrm{CO}_{2}$. Cells were treated with increasing doses of standard chemotherapeutics GEM, CPX, 5-Flourouracil (5-FU), and Cisplatin for two cycles of each $72 \mathrm{~h}$. Control cells were added medium only. Biomass quantification was done after staining residual epithelial cells with $0.2 \%$ crystal violet and subsequent measurement at $570 \mathrm{~nm}$ (Roth, Karlsruhe, Germany). Lymphoma cells' viability was calculated after Calcein AM staining and subsequent fluorescence measurement at a wavelength of $485 \mathrm{~nm}$ (Glomaxx, Promega, Mannheim, Germany) [19]. In some experiments, phenotypic changes (determined as total amounts of target antigens after cell membrane permeabilization) as well as levels of immunogenic cell death (ICD) were determined upon $24 \mathrm{~h}$ treatment at doses corresponding to $\mathrm{IC}_{30}$ values. Supernatants were collected and amounts of high-mobility group protein 1 (HMGB1) were measurement by ELISA according to the manufacturers' instructions (Abbexa, Cambridge, UK). Levels of surface bound Calreticulin (CalR, Biozol, Eching, Germany) as additional ICD marker were determined by flow cytometry and confocal laser scanning microscopy, respectively (Zeiss, Jena, Germany) using $20 x$ objectives. In this analysis, CalR positivity (green fluorescence) was scored in 5 high-power fields, with each field having at least 50 DAPI stained cells (blue fluorescence).

\section{$\mathrm{MLH}^{-/-}$mouse model}

Homozygous mice were obtained by breeding heterozygous males and females of the $\geq \mathrm{F} 5$ generation, originally 
obtained from the NCI mouse repository. All animals received standard laboratory chow and free access to water. Mice were bred in the animal facilities (University of Rostock) under specified pathogen-free conditions. Trials were performed in accordance with the German legislation on protection of animals and the Guide for the Care and Use of Laboratory Animals (Institute of Laboratory Animal Resources, National Research Council; NIH Guide, vol.25, no.28, 1996; approval number: LALLF M-V/TSD/7221.3-1.1-053/12-1 and 026/17). MLH1 genotyping was done according to [20].

\section{Vaccine preparation $\&$ in vivo vaccination protocol}

Vaccine preparation was done as previously described [17]. Briefly, outgrowing allografts were lysed using repetitive freeze/thaw cycles $(n=4)$. Protein lysates were gamma irradiated (60 Gy) and frozen immediately in aliquots at $-80{ }^{\circ} \mathrm{C}$ before in vivo application.

Prophylactic approach: Mice (8-10 weeks old) received a single injection of CPX (120 mg/kg bw, i.p., $n=9$ mice) or GEM (100 mg $/ \mathrm{kg}$ bw, i.p., $\mathrm{n}=9$ mice) prior to vaccination $(-24 \mathrm{~h})$. Thereafter, the vaccine was given repetitively by subcutaneous injections $(10 \mathrm{mg} / \mathrm{kg}$ bw, s.c., qw $1-4)$. Control mice were only given GEM or CPX ( $n=4$ mice per group) in equivalent doses. Vaccination was continued until tumor development (monthly injections: $2.5 \mathrm{mg} / \mathrm{kg} \mathrm{bw})$.

Therapeutic approach: Mice who had gastrointestinal tumors (GIT) confirmed by small animal ${ }^{18}$ F-FDG PET/ CT imaging [17] were treated by chemo-immunotherapy. Mice received a single injection of GEM $(-24 \mathrm{~h}, 100 \mathrm{mg} /$ $\mathrm{kg}$ bw, i.p., $n=5$ mice) followed by four weekly injections of the vaccine $(10 \mathrm{mg} / \mathrm{kg}$ bw, s.c.) in the first phase. Vaccination was continued $(2.5 \mathrm{mg} / \mathrm{kg}$ bw, biweekly) until tumors progressed. PET/CT imaging was repeated on days 28 or 35 of therapy. Control mice received single injections of GEM (100 mg/kg bw, i.p., $n=3$ mice) or vaccine $(10 \mathrm{mg} / \mathrm{kg}$ bw, s.c., $4 \mathrm{x} /$ once a week, followed by biweekly injections at $2.5 \mathrm{mg} / \mathrm{kg}$ bw). Blood samples were taken before treatment (prophylactic and therapeutic) and regularly during the experiment (day 28, 56, and 84). Tumor-bearing mice were sacrificed. Blood samples, tumors and spleens were taken from all animals for further analysis.

\section{PET/CT imaging}

PET/CT imaging scans were performed on a small animal PET/CT scanner (Inveon PET/CT, Siemens Medical Solutions, Knoxville, TN, USA) according a standard protocol. Mice with suspected GIT ( $N=5 /$ per group) were anaesthetized using isoflurane ( $4 \%$ for induction and $1-2,5 \%$ maintenance during preparation and scanning) and were injected intravenously with a mean dose of $17.12 \pm 1.81 \mathrm{MBq}\left[{ }^{18} \mathrm{~F}\right] \mathrm{FDG}$ via a custom-made micro catheter placed in the tail vein. After an uptake period of $60 \mathrm{~min}$, mice were imaged in prone position for $15 \mathrm{~min}$ as described [17]. Throughout the imaging session, respiration of the mice was controlled and body temperature was constantly kept of $38^{\circ} \mathrm{C}$ via a heading pad. The PET image reconstruction method consisted of a 2-dimensional ordered subset expectation maximization algorithm (2D-OSEM) with four iterations and 6 subsets. Attenuation correction was performed on the basis whole body $\mathrm{CT}$ scan and a decay correction for $\left[{ }^{18} \mathrm{~F}\right]$ was applied. PET images were also corrected for random coincidences, dead time and scatter. Tumor volumes and SUVs were determined using Inveon Research Workplace 4.2 software.

\section{Flow cytometric phenotyping}

Blood samples were taken routinely from the retrobulbar venous plexus of vaccinated and control mice. Blood samples were stained with a panel of conjugated monoclonal antibodies (mAb, $1 \mu \mathrm{g}$ each) followed by lysis of erythrocytes (155 mM NH $\mathrm{NH}_{4} \mathrm{Cl}$ (MERCK Millipore, Darmstadt, Germany), $10 \mathrm{mM} \mathrm{KHCO}_{3}$ (MERCK Millipore), $0.1 \mathrm{mM}$ EDTA (Applichem, Darmstadt, Germany). Intracellular staining was done upon incubation with $1 x$ Intracellular Staining Perm Wash Buffer (Biolegend, Koblenz, Germany). Negative controls consisted of lymphocytes stained with the appropriate isotypes (Biolegend). Cultured tumor cell lines were phenotyped with FITC-, PE-, APC-, PE-Cy7-, or APC-Cy7-labeled mAbs as follows: PD1, PD-L1, CTLA-4, LAG-3, TIM-3, IDO-1, IFN- $\gamma$, and TNF- $\alpha$ (Biolegend). Cells were washed, resuspended in PBS and analyzed by flow cytometry on a FACS Verse Cytometer (BD Pharmingen). Data analyses were performed using BD FACSuite software (BD Pharmingen).

\section{Immunofluorescence}

Cryostat sections of $4 \mu \mathrm{m}$ were air-dried and fixed in cold pure methanol for $8 \mathrm{~min}$. Unspecific binding sites were blocked in 2\% BSA (Roth) for $2 \mathrm{~h}$ followed by incubation with $1 \mu \mathrm{g}$ of the following FITC- and PE-labeled mAbs: CD4, CD8 $\alpha$, CD11b, CD19, CD20, Gr1 (Immunotools, Friesoythe, Germany), CD11c, CD104, LAG-3, PD-1, NK1.1, F4/80, and PD-L1 (Biolegend). Sections were washed and embedded in Roti Mount Flour Care DAPI to stain nuclei (Roth, Karlsruhe). Visualization of target genes was done on a confocal laser scanning microscope (Zeiss, Jena, Germany) using 20x objectives.

\section{IFNY-ELISpot assay}

Functional immunological in vitro assays included IFNy ELISpot and a flow cytometric cytotoxicity assay. All procedures were done as described [17]. Briefly, MLH1 ${ }^{-1}$

target cells were co-cultured with peripheral blood leukocytes or splenocytes $\left(1 \times 10^{4} /\right.$ well $)$ were added to targets in triplicates and overnight. Upon visualization, pots 
were counted using an ELISpot reader. Presented are the numbers of IFN $\gamma$-secreting cells per 10,000 effector cells corrected for background levels (no target cells and no effector cells, usually $\leq 5$ spots/well).

\section{Procartaplex cytokine assay}

A panel of plasma cytokine levels from treated and control mice were determined according to the manufacturer's instructions of the Procartaplex ${ }^{\mathrm{Tn}}$ multiplex immunoassay. Measurement as well as cytokine quantification was done on a Bioplex 2000 (Bio-Rad Laboratories $\mathrm{GmbH}$, Munich, Germany) in combination with the Bio-Plex Manager Software.

\section{Statistics}

All values are expressed as mean $\pm \mathrm{SD}$. Differences between individual treatment schedules in vitro were examined by applying one way ANOVA (Holm Sidak method). After proving the assumption of normality (Kolmogorov-Smirnov test), differences between treated and control mice were determined using the unpaired Student's $t$-test. Kaplan-Meier survival analysis was done by applying log rank test. The tests were performed by using Sigma-Stat 3.0 (Jandel Corp, San Rafael, CA). The criterion for significance was set to $p<0.05$.

\section{Results}

\section{In vitro drug selection for chemo-immunotherapy}

In a preliminary in vitro screening, $\mathrm{MLH}^{-1-}$ cell lines were exposed to increasing drug concentrations (representative dose response curves of $2 / 3$ cell lines are shown in Fig. 1a). All cell lines showed high responsiveness towards GEM, with $\mathrm{IC}_{50}$ levels below $0.1 \mu \mathrm{M}$ (Table 1). A more individual response pattern was seen after Cisplatin and 5-FU treatment, with $\mathrm{MLH1}^{-/-} 1351$ lymphoma cells being more vulnerable towards 5 -FU than the epithelial cells (Table 1). In line with their molecular signature, the tested cell lines were completely resistant towards CPX, even after two cycles at a dose of $>300 \mu \mathrm{M}$. Abundance of immune-checkpoint molecules was quite heterogeneous between cells (Fig. 1b). GEM and 5-FU reduced amounts of intracellular IDO- 1 in $2 / 3$ cases (Fig. 1b). The altered immune phenotype was accompanied by increased levels of surface bound CalR (Fig. 1c) as well as elevated HMGB1 secretion (Fig. 1d) indicative for induction of ICD [21]. Effects were most prominent after GEM exposure, while CPX and 5-FU had minor influence on these markers.

To examine the effect of GEM and CPX on normal cells' viability, leukocytes were cultured in the presence of different low concentrations for $24 \mathrm{~h}$ and $48 \mathrm{~h}$, respectively (data not shown). No cytotoxicity was observed providing a ready basis for subsequent in vivo preconditioning.

\section{Chemoprevention delays tumorigenesis by long-term} immune modulation

Above data hint towards strong cytotoxic activity of selected drugs against $\mathrm{MLH1}^{-/-}$- target cells without impairing normal cells' viability. We therefore examined the immune modulatory activity of chemotherapeutics when given before (= prophylactic approach) and after tumor establishment (= therapeutic approach) in vivo. The agents GEM and CPX were selected on the basis of supposed immunomodulatory activities such as reducing MDSC numbers in vivo and augmenting antigen-specific cellular antitumor immunity to promote $\mathrm{T}$ helper immunity [22]. Chemotherapeutics were given once before vaccination at doses of 100 and $120 \mathrm{mg} / \mathrm{kg}$ bw, respectively, to boost tumor immunity. Control mice were given single injection of either substance at given doses. A detailed treatment schedule is given in Fig. 2.

Preconditioning with GEM or CPX prior to vaccination delayed tumorigenesis, with resulting prolonged survival (Fig. 3a). 33\% of mice even remained tumor free until the experimental endpoint in the GEM vaccine group vs. only $11 \%$ in CPX pretreated mice (vs. 15.4\% vaccination alone). Additional differences were seen in tumor distribution between these treatment groups. Mice pretreated with CPX before vaccination developed lymphomas more frequently than GIT (5/9 vs. 2/9 mice, respectively). Of note, lymphomagenesis was delayed ( $34.3 \pm 6.9$ weeks) compared to GEM + vaccination $(23.5 \pm 13.4$ weeks $)$ and vaccination alone (30.8 \pm 10.0 weeks). Vice versa, GEM preconditioning resulted in more frequent gastrointestinal tumor formation (4/9 mice vs. lymphomas: $2 / 9$ mice). Here again, tumorigenesis was slightly decelerated $(44.6 \pm 4.6$ weeks vs. $42.0 \pm 8.5$ weeks vaccination alone) (Table 2 ).

Single prophylactic application of GEM or CPX without subsequent vaccination did not influence tumor formation. All mice developed tumors within the expected time frame (Table 2). Consequently, data from control mice were pooled and the presented ones refer to these groups.

\section{Immune status and tumor microenvironment upon prophylactic chemo-immunotherapy}

Prior to immune monitoring during prophylactic vaccination, the immune status of $\mathrm{MLH} 1^{-/-}$mice was examined in comparison to wildtype and heterozygous MLH1 mice (Fig. 3b). This analysis revealed marked differences in certain immune cell subsets, with a trend towards higher

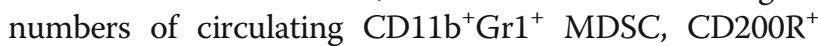
monocytes - and immune-checkpoint-molecule positive cells - all of them known as inhibitory receptors with the capacity to down-modulate cellular activation [23, 24]. Of note, this imbalance between individual cellular subtypes was more evident in aged mice ( $\geq 32$ weeks), indicative for a slightly impaired immune function in $\mathrm{MLH} 1^{-1-}$ mice irrespective of tumor stage (Fig. $3 \mathrm{~b}$ ). 


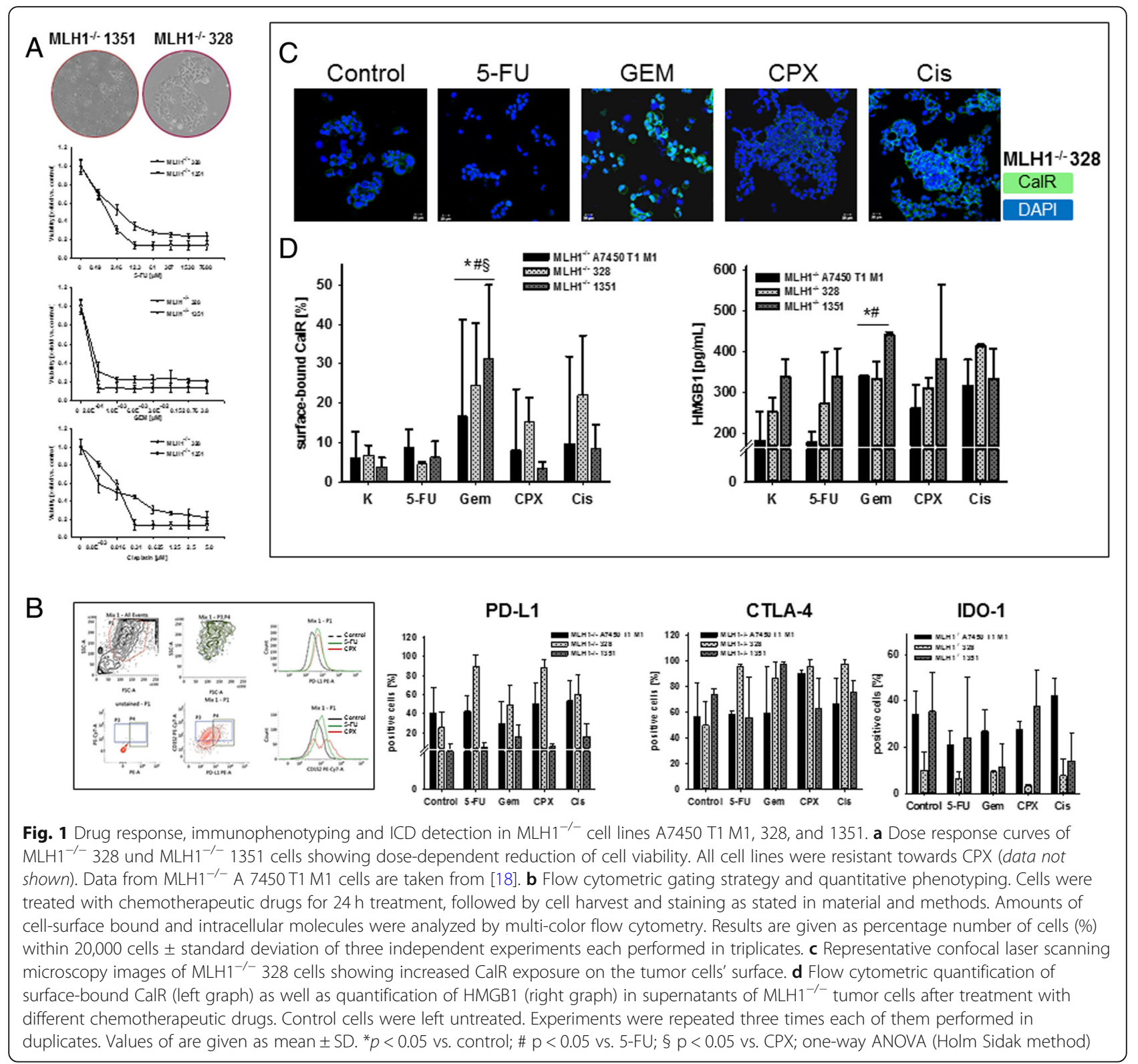

Subsequent immune monitoring (Fig. 3c, upper panel) during vaccination revealed increased relative numbers of $\mathrm{CD}^{+}{ }^{+} \mathrm{CD} 4^{+} \mathrm{T}$ helper and $\mathrm{CD} 3^{+} \mathrm{CD}^{+}$cytotoxic $\mathrm{T}$ cells in mice pretreated with GEM or CPX (Fig. 3c lower panel). Immunological changes were evident until day

Table 1 In vitro drug response of $\mathrm{MLH}^{-/-}$cell lines

\begin{tabular}{llll}
\hline Drug & \multicolumn{1}{l}{$\mathrm{IC}_{50}$ value $[\mu \mathrm{M}]$} & \\
\cline { 2 - 4 } & $\mathrm{MLH1}^{-/-} \mathrm{A} 7450 \mathrm{T1} \mathrm{M1}^{\mathrm{a}}$ & $\mathrm{MLH1}^{-/-} 328$ & $\mathrm{MLH}^{-/-} 1351$ \\
\hline GEM & 0.05 & 0.07 & $<0.02$ \\
Cisplatin & 0.63 & 0.05 & 0.06 \\
5-FU & 2.15 & 3.57 & 1.00 \\
$\mathrm{CPX}$ & $>300$ & $>300$ & $>300$ \\
\hline
\end{tabular}

GEM Gemcitabin, 5-FU 5-Fluorouracil, CPX Cyclophosphamide; ${ }^{a}$ [18]
63 of vaccination, but declined afterwards (Fig. 3c). Assessment of MDSC revealed no significant changes between the individual treatment groups.

Thereafter, spleens from vaccinated and control mice were analyzed with respect to immune cell subpopulations. Spleens from vaccinated mice with CPX or GEM pretreatment had higher relative numbers of $\mathrm{T}$ cells and a trend towards lower MDSC numbers (Fig. 3d). Likewise, percentages of Treg as well as LAG- $3^{+}$cells were lower in these groups and most evident in the GEM + vaccine group, accompanied by low amounts of IL-6, but higher levels of the Th2-cytokine IL-13 (Fig. 4). Of note and as expected, cytokine patterns differed between individuals depending on whether mice developed tumors or not (Fig. 4). 


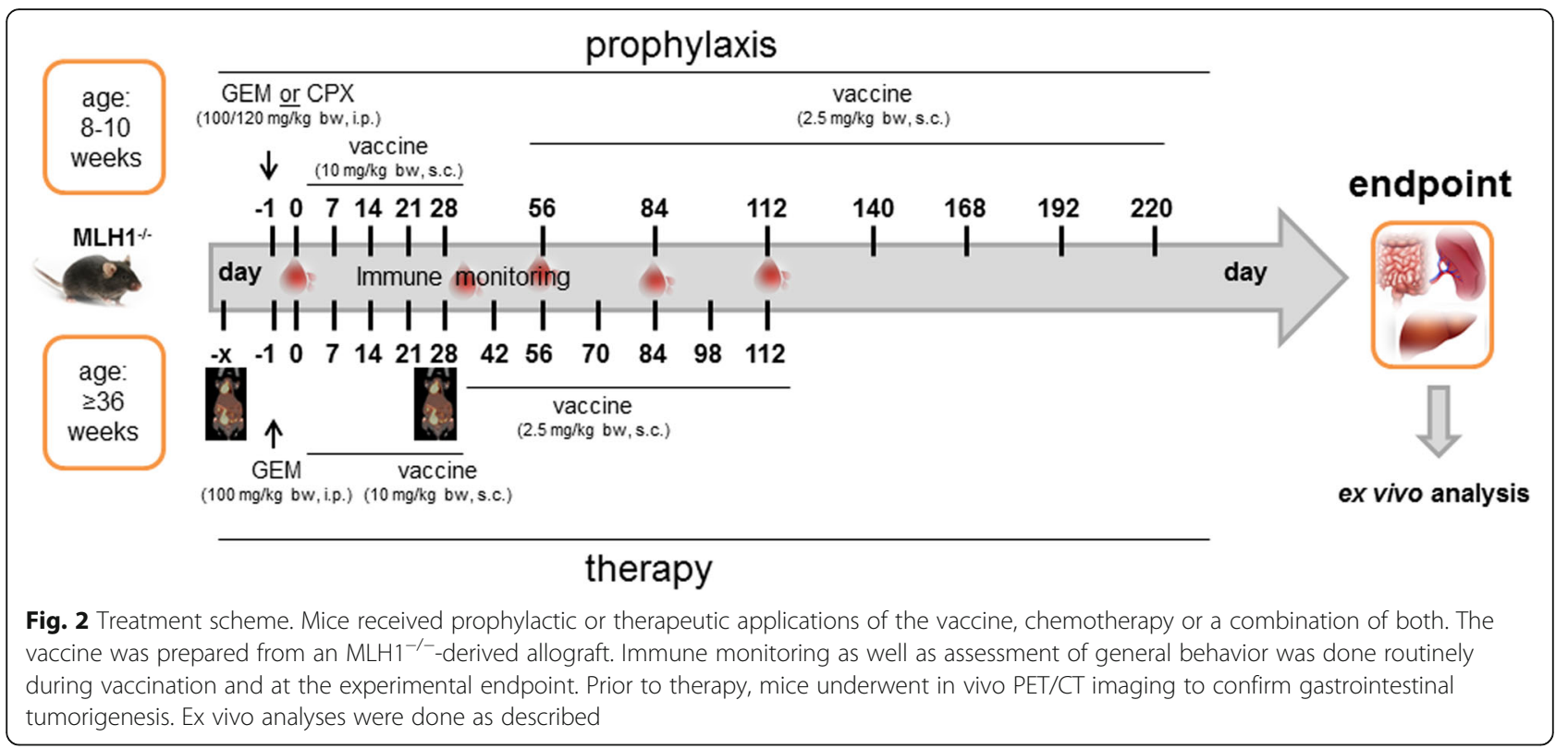

Next, the tumor microenvironment was studied in detail. All vaccinated mice had higher numbers of infiltrating CD11 $\mathrm{c}^{+}$DC (Fig. 5). Mice preconditioned with GEM or CPX had additionally lower amounts of CD11 $\mathrm{b}^{+}$infiltrates and no MDSC in the tumor microenvironment. Numbers of tumor-infiltrating CTL increased only marginally in the combination. NK cells were interestingly higher in the GEM + vaccine group than in the CPX + vaccine group and almost absent in control and vaccinated tumors without pretreatment. Immune checkpoint molecule PD-L1 was highly upregulated on infiltrating cells in the $\mathrm{MLH}^{-/-}$tumor microenvironment.

\section{Therapeutic chemo-immunotherapy}

Next, $\mathrm{MLH}^{-1-}$ mice with confirmed GIT were assigned to chemo-immunotherapy, based on the successful prevention of tumorigenesis by preconditioning with GEM. Tumor formation in the gastrointestinal tract was confirmed by in vivo imaging technique using ${ }^{18} \mathrm{~F}$-FDG PET/CT. Mice developed $3.0 \pm 1.7$ tumor nodules in average (vs. vaccination alone: $3.5 \pm 1.7$ tumors) with a mean tumor volume of $110.1 \pm 90.6 \mathrm{~mm}^{3}$ at start of treatment (vs. vaccination alone: $93.4 \pm 74.8 \mathrm{~mm}^{3}$ ). GEM was given $24 \mathrm{~h}$ before vaccination, followed by repetitive local application of the vaccine. This regimen was well tolerated without having any serious side effects, like weight loss, anemia, or gastrointestinal disorders. Repeated in vivo imaging at day 28 or 35 of therapy revealed disease control which was, however, comparable to vaccination alone (26\% growth reduction vs. vaccination alone: $31 \%$ growth reduction) (Fig. 6a). In one case, tumor nodules completely regressed and this mouse remained tumor free until the experimental endpoint (>
40 weeks) (Fig. 6a). Overall survival was quite similar between the two treatment arms, but significantly longer than control mice either given GEM once or left untreated (Fig. 6b).

Accompanying immune phenotyping revealed differences between treatment groups, with lower numbers of circulating MDSCs, PD-L1 ${ }^{+}$as well as $\mathrm{LAG}^{+}$immune cells in the GEM + vaccine group (Fig. 7a). NK cell numbers even remained low in this group of mice, while numbers of $\mathrm{CD}^{+} \mathrm{CD}^{+}$cytotoxic $\mathrm{T}$ cells gradually increased. This altered immune phenotype was also detectable in spleens (Fig. 7b). Here again, T cell numbers (both Th and CTL) increased after chemo-immunotherapy, while immune regulatory cells were found to be low. Amounts of PD $-1^{+}$and LAG- $3^{+}$cells did not significantly change during vaccination either with or without GEM pretreatment (Fig. 7b). Likewise, plasma cytokine levels were comparable between both treatments, with a tendency towards reduced Th2-directed responses were comparing with controls (Fig. 7c).

Immunological changes contributed to differential responses in ELISpot IFN $\gamma$ assays. Lymphocytes from GEM + vaccine mice specifically recognized $\mathrm{MLH}^{-1-}$ target cells, with even higher numbers than lymphocytes from vaccinated mice without preconditioning (Fig. 7d). Along with the observed low amount of circulating NK cell numbers, recognition of NK cell target YAC-1 could be largely neglected.

\section{Tumor microenvironment}

Detailed assessment of the tumor microenvironment from treated mice identified increased numbers of infiltrating $\mathrm{CD}^{+}$and $\mathrm{CD} 8^{+} \mathrm{T}$ cells in both treatment arms, 


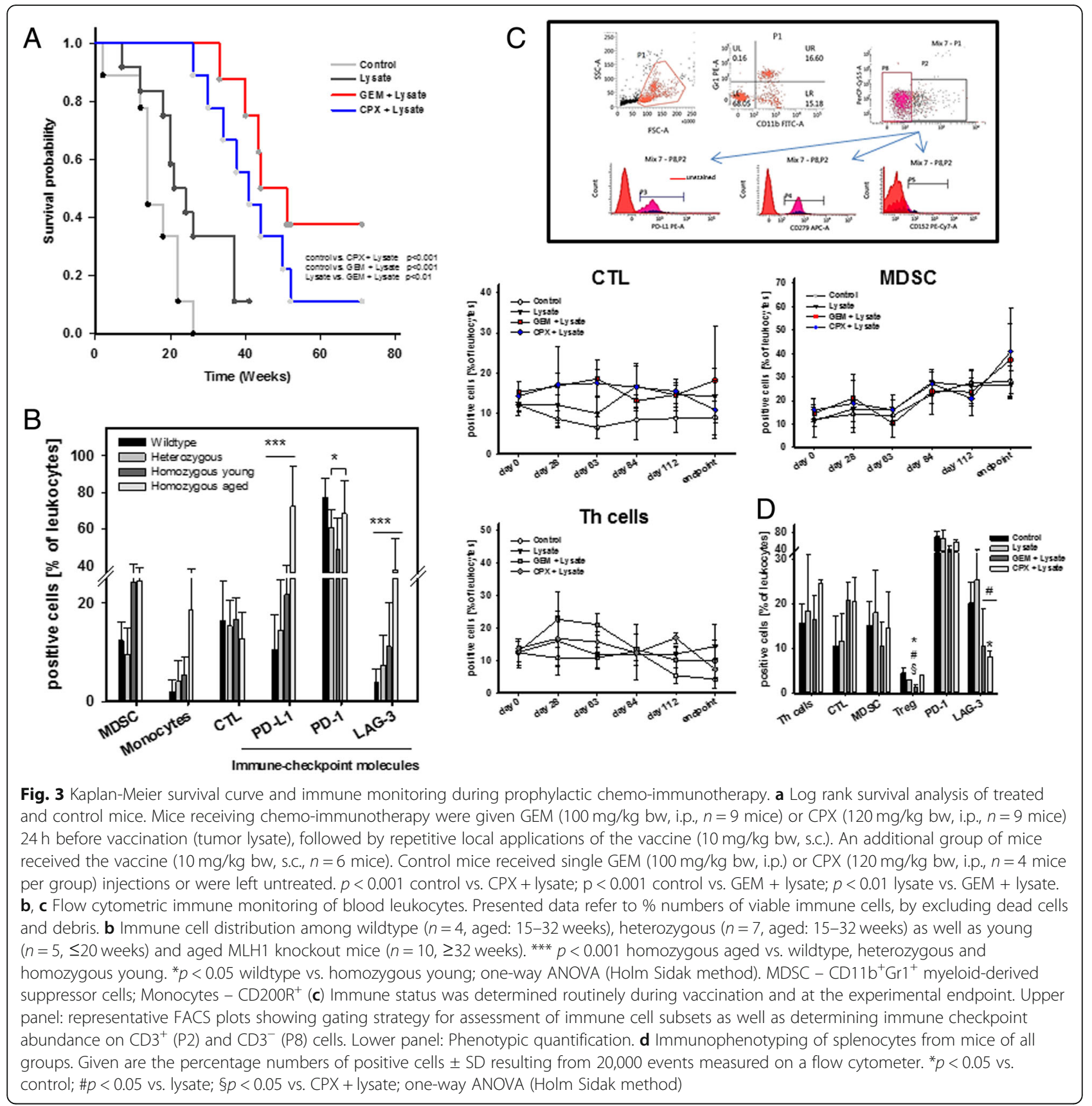

Table 2 Effect on prophylactic chemo-immunotherapy on tumorigenesis and tumor spectrum in $\mathrm{MLH}^{-/-}$mice

\begin{tabular}{|c|c|c|c|c|c|c|}
\hline \multirow[t]{2}{*}{ Intervention } & \multicolumn{2}{|c|}{ mean age of onset [weeks \pm SD] } & \multicolumn{3}{|c|}{ tumor type [\%] } & \multirow{2}{*}{$\begin{array}{l}\text { mice }[\%] \\
\text { tumor free }\end{array}$} \\
\hline & Lymphoma & GIT & Lymphoma & GIT & other & \\
\hline control $^{\mathrm{a}}$ & $25.3 \pm 11.7$ & $35.5 \pm 9.3$ & 62.1 & 34.7 & 3.2 & 0.0 \\
\hline lysate & $30.2 \pm 10.0$ & $47.4 \pm 8.5$ & 51.7 & 33.3 & 0.0 & 15.0 \\
\hline GEM + vaccine & $23.5 \pm 13.4$ & $53.4 \pm 14.1$ & 22.2 & 44.4 & 0.0 & 33.3 \\
\hline$C P X+$ vaccine & $34.3 \pm 6.9$ & $47.7 \pm 5.9$ & 55.5 & 33.3 & 0.0 & 11.1 \\
\hline
\end{tabular}

${ }^{\mathrm{a}} \mathrm{GEM}$ and $\mathrm{CPX}$ treated mice without vaccine were grouped together, GIT gastrointestinal tumor 

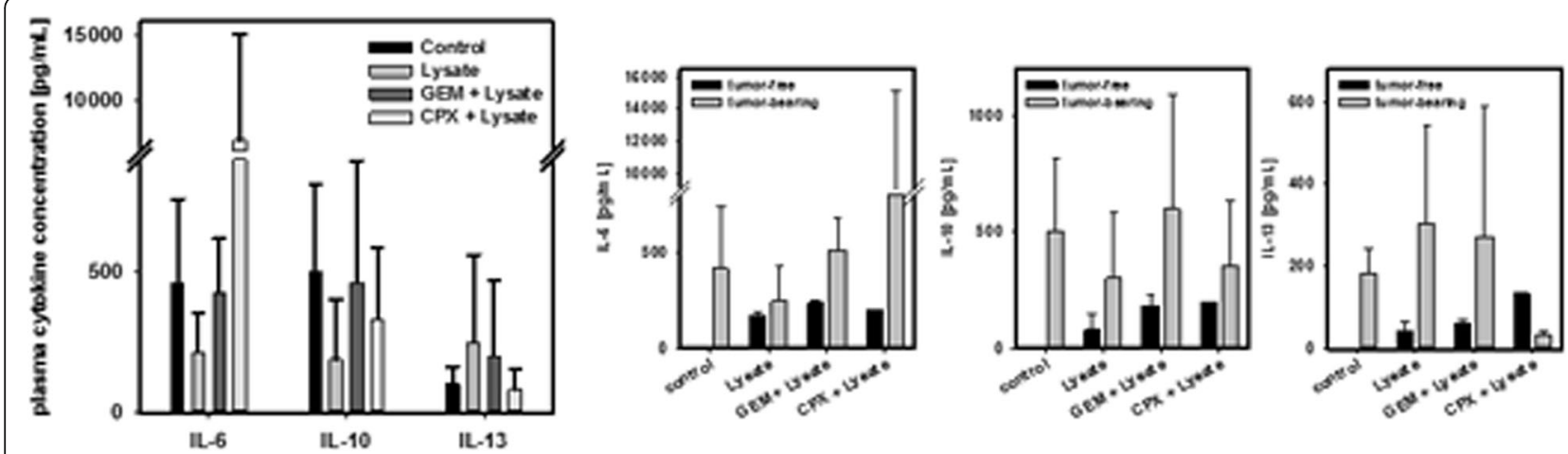

Fig. 4 Plasma cytokine levels of IL-6, IL-10 and IL-13 from mice with prophylactic chemo-immunotherapy and controls (upper graph). Differences between tumor-free and tumor-bearing mice (lower graphs). Plasma samples were collected th the experimental endpoint and cytokine levels were determined as described in material and methods

but at higher levels upon chemo-immunotherapy (Fig. 8a, c). However, LAG-3 was also upregulated on infiltrating immune cells. With regard to other immune regulatory cellular infiltrates, differences were apparent between vaccinated mice and those treated with the combination

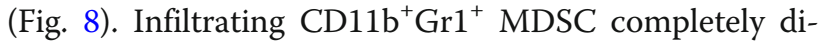
minished in the GEM + vaccine group $(2.0 \pm 3.8$ cells/ HPF vs. vaccine: $6.3 \pm 6.9$ cells/HPF vs. control: $53.1 \pm$ 63.1 cells/HPF), residual myeloid cells were mostly $\mathrm{Gr}^{+} \mathrm{CD} 11 \mathrm{~b}^{-}$granulocytes. CD $11 \mathrm{~b}^{+}$myeloid cells, if any, had no expression of PD-L1 and may thus not be regarded as immunosuppressive response. In support of this finding, levels of $\mathrm{CD}_{11 \mathrm{c}^{+}} \mathrm{DC}$ increased upon (chemo-) immunotherapy (58.2 \pm 31.1 cells/HPF vs. vaccine: $107.5 \pm 70.1$ cells/HPF vs. control: $45.0 \pm 16.5$ cells/ $\mathrm{HPF}$ ), while numbers of $\mathrm{F} 4 / 80^{+}$(tumor-associated) macrophages decreased $(50.3 \pm 46.1$ cells/HPF vs. vaccine: $52.7 \pm 48.2$ cells/HPF vs. control: $68.3 \pm 30.2$ cells/HPF), indicative for phenotypic (and eventually functional) polarization (Fig. 8).

\section{Discussion}

Recent years have seen much progress in understanding the interplay of chemotherapy and immunotherapy as well as in identifying drugs with immunomodulatory potential. While most agents failed to interfere positively

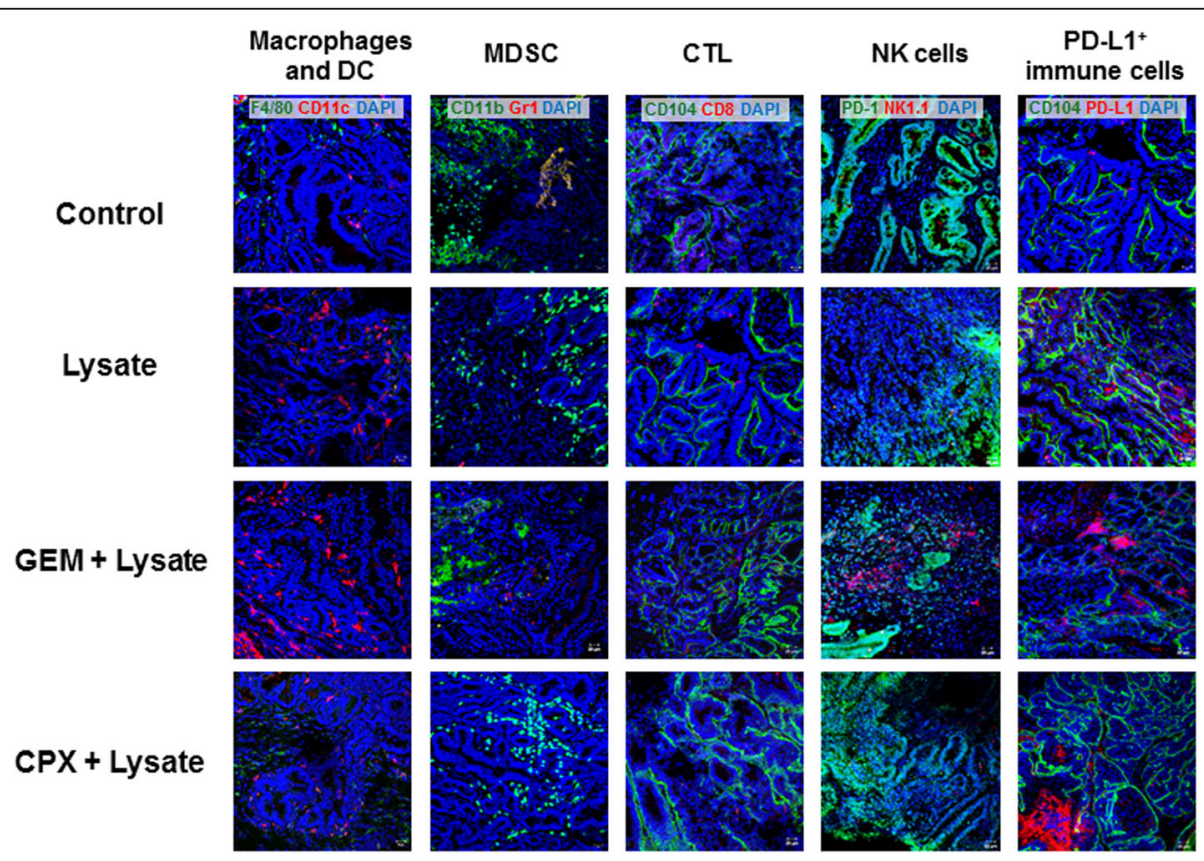

Fig. 5 Representative micrographs of tumor microenvironment after prophylactic chemo-immunotherapy. GIT were resected from mice of all groups, cryopreserved and cut into $4 \mu \mathrm{m}$ slides for immunofluorescence analysis. Upon blocking, slides were stained with fluorochrome-labeled monoclonal antibodies and DAPI for nuclear staining. Pictures were done on a confocal laser scanning microscope (Zeiss) using 20x objectives 


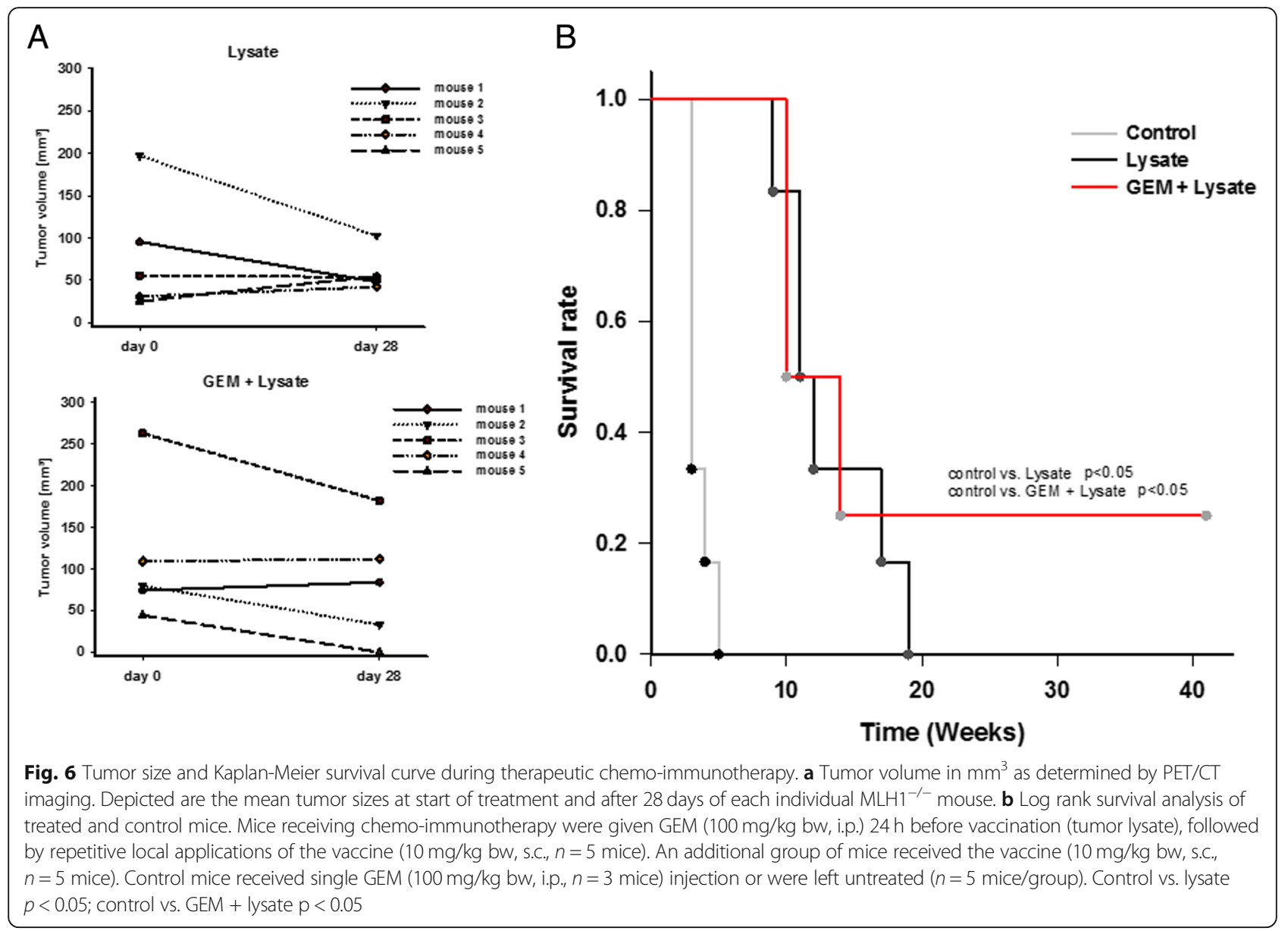

with the immune system [22], GEM and CPX are two prominent candidates likely boosting vaccination and thus improving therapy. GEM assists in elimination of tumor-induced MDSC via apoptosis/necrosis and may even prevent MDSC maturation and activation [25]. GEM was also shown to support DC vaccination in murine pancreatic cancer models and in a phase I clinical study using WT1 peptide as vaccination antigen [26]. Besides, we and others were able to show that GEM exerts direct toxic effects towards MMR-D tumor cells of different origin (i.e. solid tumor vs. hematological malignancies) $[27,28]$. Inhibition of cell proliferation was achieved at concentrations well below plasma levels under standard therapy [27] and accompanied by classical signs of ICD induction (exposure of CalR, HMGB1 release), the latter shown here on three low-passage murine MMR-D cell lines. CPX by itself has opposite effects: A single low dose of CPX given 1 to 3 days before vaccination conquers tumor-induced tolerance. However, CPX concurrently with or subsequently applied attenuates $\mathrm{T}$ cell immune responses through the PD-1-PD-L1 axis [29]. Successful combination of immune-stimulating vaccination and cytotoxic therapy depends on the choice of drug as well as its ability to induce ICD upon application in the right dose and treatment schedule. On a basis of these findings, we now focused on single chemotherapy prior to vaccination. $\mathrm{MLH}^{-1-}$ mice, representing a valuable preclinical model for designing vaccine trials, were given chemotherapy once before vaccination, following recommendations of a recent study [30].

Prophylactic chemo-vaccination prolonged tumor-free time and accordingly overall survival. Of note, one third of mice exposed to GEM before vaccination remained completely tumor-free until the experimental endpoint. This effective tumor prevention was accompanied by increasing numbers of circulating $\mathrm{T}$ cells, lasting up to 2 month after start of treatment. Of note, vaccination alone or CPX preconditioning did not yield comparable results, again highlighting the potential of GEM as combinatorial agent for immunotherapy.

Another interesting finding of this study was the difference on type of tumor formation. Mice with CPX preconditioning gave primarily rise to lymphomagenesis and thus largely covered the expected tumor spectrum. Vice versa, chemo-immunotherapy with GEM reduced 

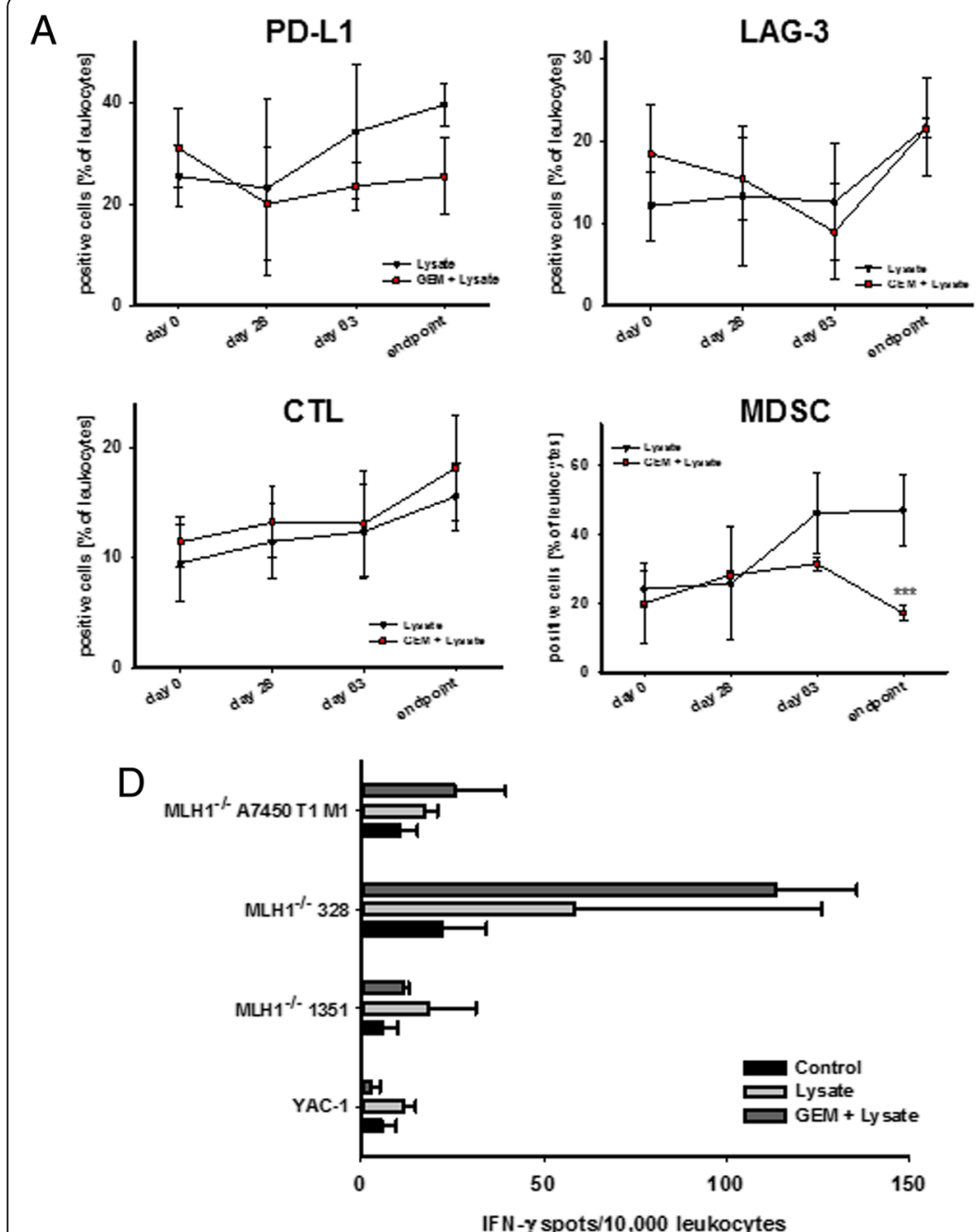

B
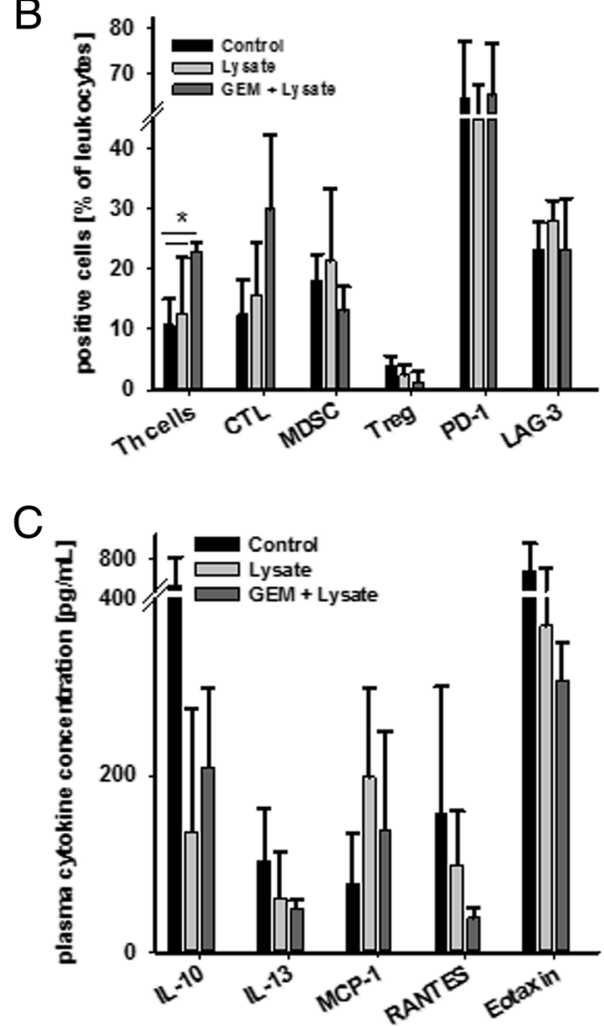

Fig. 7 Immune monitoring, plasma level and IFN- $\gamma$ ELISpot during and after therapeutic chemo-immunotherapy. a Flow cytometric immune monitoring of blood leukocytes was done routinely during vaccination and at the experimental endpoint. Given are the percentage numbers of positive cells \pm SD resulting from 20,000 events measured on a flow cytometer. ${ }^{* *} p<0.001$ vs. control; T-test. b Immunophenotyping of splenocytes from mice of all groups. Given are the percentage numbers of positive cells \pm SD resulting from 20,000 events measured on a flow cytometer. * $p<0.05$ vs. control; one-way ANOVA (Holm Sidak method). c Plasma cytokine levels of IL-10, IL-13, MCP-1, RANTES, and Eotaxin from mice with therapeutic chemo-immunotherapy and controls. Plasma samples were collected at the experimental endpoint and cytokine levels were determined as described in material and methods. d Number of IFN- $\gamma$ secreting cells after over-night incubation of splenocytes (=effector cells) and tumor target cells (MLH1 ${ }^{-/} 7450 \mathrm{T1} \mathrm{M1}, \mathrm{MLH}^{-/-} 328, \mathrm{MLH}^{-/}$1351, and YAC-1). Lymphocytes were isolated from mice of all groups showing increased reactivity post treatment

lymphomagenesis and also decelerated GIT formation. In this particular group however, lymphomas were early detectable, with one mouse showing pathological signs of an advanced malignancy 5 weeks after start of treatment. One may thus speculate that some premalignant, yet clinically not detectable, lymphatic cells were already present at vaccine initiation, finally contributing to treatment failure. Although proven to be effective in the in vitro cell culture system, single cycle chemotherapy with GEM was most likely not sufficient to inhibit cell growth in vivo. The aggressive nature of MMR-D lymphomas, making mice condemned to die within a short period of time, may additionally explain this result. Also this finding supports previous observations on only marginal entity-overlapping antitumoral capacity in the therapeutic situation [17]. Hence, vaccination against lymphomas is only effective in mice before evolving any oncogenic events. Molecularly, this can be attributed to the rapid and ongoing accumulation of novel (escape) mutations in MMR-D tumor cells [31-34]. Although the number of cases included here is far too low to make personalized recommendations, we would like to strengthen that prophylactic vaccines should be given early in life to maximize the potential to delay or even 


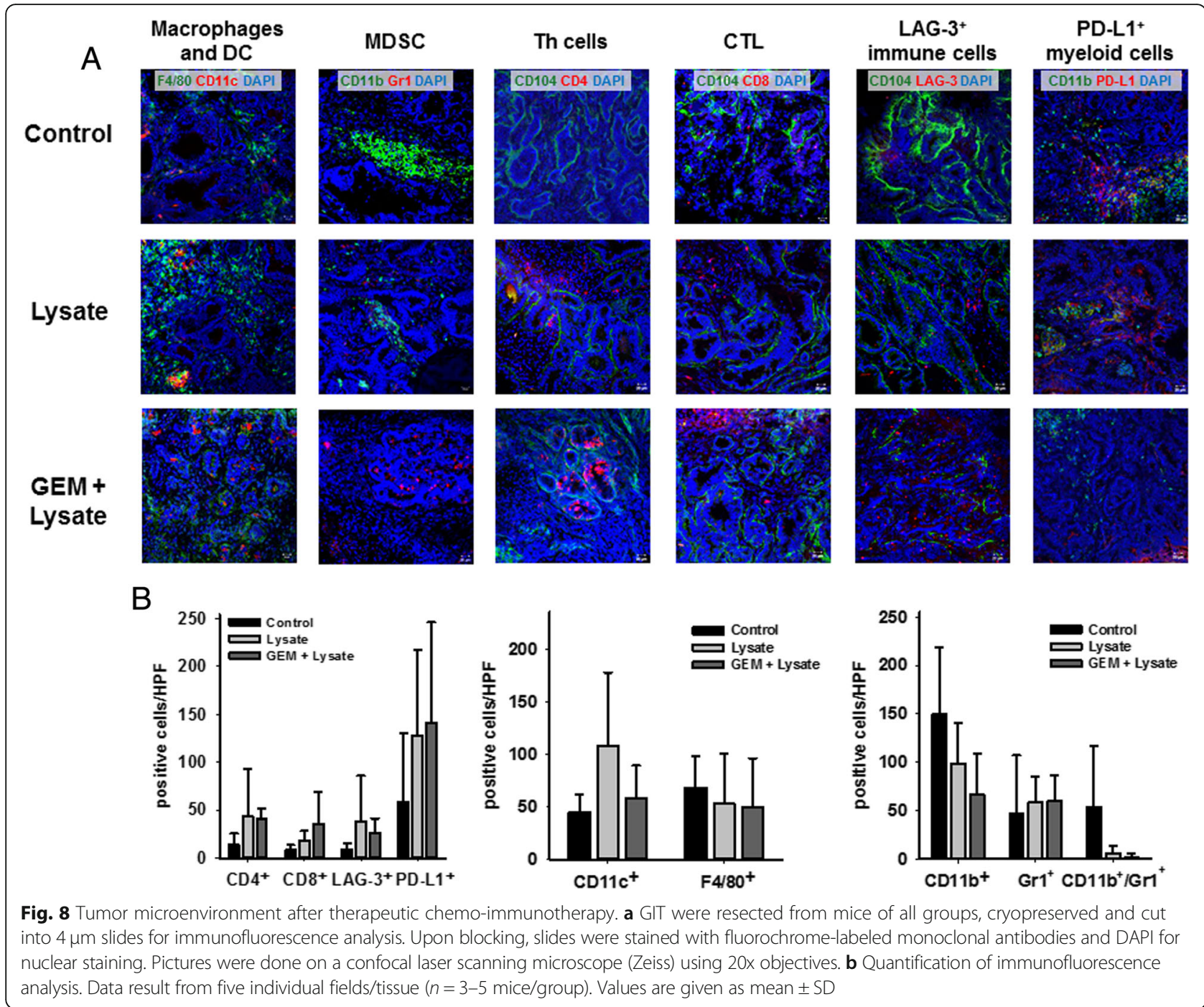

prevent tumor formation. These findings are in agreement with experiences from other vaccination approaches to impede Human papillomavirus (HPV)-related cancer [35]. In here, HPV vaccination is efficient and potentially lifesaving if administered to females naive or unexposed to vaccine HPV types [36, 37]. This might be of particular significance for patients diagnosed with CMMR-D, likely to benefit from immunoprevention - similar to the approaches based on regular use of aspirin or ibuprofen [38]. Along with intensified screening, outcome may be improved by earlier recognition of asymptomatic tumors that are better resectable and eventually curable [39]. Having in mind that carcinogenesis is accelerated in these patients early intervention is even more desirable.

The exact mechanism by which GEM in conjunction with the vaccine prevented tumor formation in some $\mathrm{MLH}^{-/-}$mice remains elusive. Still, interference with naturally immunosuppressive circulating as well as tissue-specific cells is feasible. In support of this, MDSC and Treg numbers were low in spleens of mice receiving this treatment arm - of note, even after several months. Vice versa, levels of splenic CTL were generally higher. This was, however, rather drug independent likely to constitute a positive spin-off with limited relevance for outcome.

Prophylactic chemo-vaccination additionally influenced the tumor microenvironment. MDSC polarization was accompanied by DC infiltration as part of the ongoing immune stimulation. Though not analyzed in detail in the current work activation of CTL is expected and may trigger a proinflammatory state [40]. Finally, these cells have the capacity to kill tumor cells directly [41]. Of note, a very recent single-arm, open-label phase I clinical trial confirmed the safety and efficacy of intratumorally injected activated DCs in patients with solid tumors [42]. In our study, immunosuppressive checkpoint molecules were upregulated in tumors of 
vaccinated mice to blunt tumor cell killing [43] and most likely explains final tumor formation in this immune-privileged microenvironment.

Overcoming the variety of immunosuppressive mechanisms pre-established in the tumor microenvironment is demanding for therapeutic approaches. Targeting therapy-induced suppressor cells may augment the long-term efficacy of vaccination. However, GEM application prior to vaccination had marginal impact on vaccine-induced tumor remission. This vaccine, providing a mixture of undefined antigens and likely to activate polyclonal immune responses, was effective in tumor cell killing by itself [44, 45]. Applying higher doses and/or more cycles of chemotherapy may improve outcome. Also, combinations of chemo-immunotherapy [46] and immune checkpoint inhibition are expected to move the field forward. Still, the complete tumor remission in one case is promising and warrants further investigations.

This approach sheds light on antitumoral mechanisms that include modulation/induction of MMR-D-specific immune responses as well as reshaping of the tumor microenvironment [47]. Hence, chemotherapy-induced cell death enhanced cross-priming, thereby increasing T-cell-driven responses either by recognizing tumor-derived neo-antigens (mutated proteins, re-activated antigens, etc.) or differentially expressed molecules (tumor-associated antigens) [48]. This was additionally proven on a functional level, in which syngeneic $\mathrm{MLH1}^{-/-}$ tumor targets evoked specific IFN- $\gamma$ release of lymphocytes from vaccinated mice +/- GEM pretreatment. Of note, we observed only minor entity-overlapping responses (i.e. GIT vs. lymphoma) providing another evidence for differentially expressed target antigens among $\mathrm{MLH}^{-/-}$tumors. Of particular interest in this context is the question whether vaccination with a lymphoma lysate would yield comparable results. However, this has to be addressed prospectively.

Finally, immune interference is a complex phenomenon. The immunosuppressive nature of the tumor microenvironment is a key limitation to therapeutic vaccination. Breaking the tolerance by depleting or 're-educating' immunosuppressive cell types remains the key to unleash antigen-specific immune responses. We here present a strategy to positively influence the choice between dominant immunosuppression versus inflammation, antigen cross-presentation, and epitope spreading that warrants further improvement.

\section{Conclusions}

This study describes a strategy to delay MMR-D driven tumorigenesis. We were able to show that combined application of low-dose chemotherapy with immunestimulating vaccination significantly prolongs survival both in a prophylactic and therapeutic setting. Depleting or 're-educating' immunosuppressive cell types in conjunction with a cellular cancer vaccine is a promising concept for prospective vaccine-tailored immunotherapeutic trials.

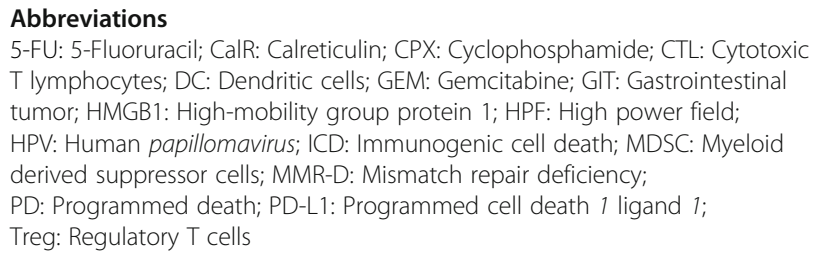

\section{Acknowledgements}

We gratefully thank Brigitte Vollmar and Bernd Krause for their continuous support in their efforts of chairing the Core Facility of Multimodal Small Animal Imaging. We also gratefully acknowledge the excellent technical assistance of Mrs. Anne Möller and Mrs. Joanna Förster. Furthermore, we thank Carina Bergner and Anja Gummesson, radiopharmacy team of the Department of Nuclear Medicine of the University Medical Centre Rostock, for providing

${ }^{18}$ F-FDG for the small animal PET/CT experiments. Lastly, we thank Mrs. Dr. Petra Muller for her kind help in performing the Procartaplex Cytokine Assay.

\section{Funding}

This work was supported by a grant from the German research foundation to CM [DFG grant number MA5799/2-1].

\section{Availability of data and materials}

The datasets used and/or analyzed during the current study are available from the corresponding author on reasonable request.

\section{Authors' contributions}

$\mathrm{CM}$ conducted the study, performed the experiments, analyzed data and wrote the manuscript; LW and IN performed in vivo and in vitro experiments; JS performed in vivo PET/CT imaging and critically revised the manuscript; CJ critically revised the manuscript. All authors read and approved the final manuscript.

\section{Ethics approval and consent to participate}

All experiments were performed in accordance with the German legislation on protection of animals and the Guide for the Care and Use of Laboratory Animals (Institute of Laboratory Animal Resources, National Research Council; NIH Guide, vol.25, no.28, 1996; approval number: LALLF M-V/TSD/7221.3-1.1-053/12-1 and 026/17)

Consent for publication

"Not applicable".

\section{Competing interests}

The authors declare that they have no competing interests.

\section{Publisher's Note}

Springer Nature remains neutral with regard to jurisdictional claims in published maps and institutional affiliations.

\section{Author details}

'Department of Medicine, Clinic III - Hematology, Oncology, Palliative Medicine, Rostock University Medical Center, Ernst-Heydemann-Str. 6, 18057 Rostock, Germany. ${ }^{2}$ Core Facility Multimodal Small Animal Imaging, Rostock University Medical Center, Schillingallee 69a, 18057 Rostock, Germany.

Received: 10 October 2018 Accepted: 6 December 2018

Published online: 10 January 2019

\section{References}

1. Ascierto PA, Brugarolas J, Buonaguro L, Butterfield LH, Carbone D, Daniele B, et al. Perspectives in immunotherapy: meeting report from the Immunotherapy Bridge (29-30 November, 2017, Naples, Italy). J Immunother cancer. England. 2018;6:69. 
2. Wrobel P, Ahmed S. Current status of immunotherapy in metastatic colorectal cancer. Int J Colorectal Dis. Germany. 2018. https://doi.org/10. 1007/s00384-018-3202-8

3. Martin Lluesma S, Graciotti M, Chiang CL-L, Kandalaft LE. Does the immunocompetent status of Cancer patients have an impact on therapeutic DC vaccination strategies? Vaccines. Switzerland. 2018;6. https:// doi.org/10.3390/vaccines6040079.

4. Chabanon RM, Pedrero M, Lefebvre C, Marabelle A, Soria JC, Postel-Vinay S Mutational landscape and sensitivity to immune checkpoint blockers. Clin Cancer Res. 2016;22:4309-21.

5. Cogdill AP, Andrews MC, Wargo JA. Hallmarks of response to immune checkpoint blockade. Br J Cancer Nature Publishing Group. 2017;117:1-7.

6. Giroux Leprieur E, Dumenil C, Julie C, Giraud V, Dumoulin J, Labrune S, et al. Immunotherapy revolutionises non-small-cell lung cancer therapy: results, perspectives and new challenges. Eur J Cancer. Elsevier Ltd. 2017;78:16-23 Available from: https://doi.org/10.1016/j.ejca.2016.12.041.

7. Dempke WCM, Fenchel K, Uciechowski P, Dale SP. Second- and thirdgeneration drugs for immuno-oncology treatment-the more the better? Eur J Cancer. England. 2017;74:55-72.

8. Galati D, Zanotta S. Empowering dendritic cell cancer vaccination: the role of combinatorial strategies. Cytotherapy. England. 2018;20:1309-23.

9. van Willigen WW, Bloemendal M, Gerritsen WR, Schreibelt G, de Vries IJM, Bol KF. Dendritic Cell Cancer Therapy: Vaccinating the Right Patient at the Right Time. Front Immunol. Switzerland. 2018;9:2265.

10. Fisher SA, Cleaver A, Lakhiani DD, Khong A, Connor T, Wylie B, et al. Neoadjuvant anti-tumor vaccination prior to surgery enhances survival. J Transl Med. England. 2014;12:245.

11. Chang K, Taggart MW, Reyes-Uribe L, Borras E, Riquelme E, Barnett RM, et al. Immune profiling of premalignant lesions in patients with lynch syndrome. JAMA Oncol. United States. 2018. https://doi.org/10.1001/ jamaoncol.2018.1482.

12. Yuza K, Nagahashi M, Watanabe S, Takabe K, Wakai T. Hypermutation and microsatellite instability in gastrointestinal cancers. Oncotarget. 2017;8: 112103-15.

13. Turajlic S, Litchfield K, Xu H, Rosenthal R, McGranahan N, Reading JL, et al. Insertion-and-deletion-derived tumour-specific neoantigens and the immunogenic phenotype: a pan-cancer analysis. Lancet Oncol. 2017;18: 1009-21. The Author(s). Published by Elsevier Ltd. This is an Open Access article under the CC BY 4.0 license; Available from: https://doi.org/10.1016/ S1470-2045(17)30516-8.

14. Grenier JM, Yeung ST, Khanna KM. Combination immunotherapy: taking cancer vaccines to the next level. Front Immunol. 2018;8:1-9.

15. Adah D, Hussain M, Qin L, Qin L, Zhang J, Chen X. Implications of MDSCstargeting in lung cancer chemo-immunotherapeutics. Pharmacol Res. Elsevier Ltd. 2016;110:25-34 Available from: https://doi.org/10.1016/j.phrs. 2016.05.007

16. Weber R, Fleming V, Hu X, Nagibin V, Groth C, Altevogt P, et al. MyeloidDerived Suppressor Cells Hinder the Anti-Cancer Activity of Immune Checkpoint Inhibitors. Front Immunol. Switzerland. 2018:9:1310.

17. Maletzki C, Gladbach YS, Hamed M, Fuellen G, Semmler M-L, Stenzel J, et al. Cellular vaccination of $\mathrm{MLH}^{-/}$mice-an immunotherapeutic proof of concept study. Oncoimmunology. 2018;7. https://doi.org/10.1080/2162402X. 2017.1408748

18. Maletzki C, Beyrich F, Hühns M, Klar E, Linnebacher M. The mutational profile and infiltration pattern of murine $\mathrm{MLH}^{-1-}$ tumors - concurrences, disparities and cell line establishment for functional analysis. Oncotarget. 2016;7. https://doi.org/10.18632/oncotarget.10677.

19. Maletzki C, Klier U, Marinkovic S, Klar E, Andrä J, Linnebacher M. Host defense peptides for treatment of colorectal carcinoma-a comparative in vitro and in vivo analysis. Oncotarget. 2014;5(12):4467-79.

20. Edelmann W, Yang K, Kuraguchi M, Edelmann W, Yang K, Kuraguchi M, et al. Tumorigenesis in Mlh1 and Mlh1 / Apc1638N Mutant Mice Tumorigenesis in Mlh1 and Mlh1 / Apc1638N Mutant Mice 1; 1999. p. 1301-7.

21. Johnson TS, Mcgaha T, Munn DH. Chemo-immunotherapy: role of Indoleamine 2,3-dioxygenase in defining immunogenic versus Tolerogenic cell death in the tumor microenvironment. Adv Exp Med Biol United States. 2017;1036:91-104.

22. Emens LA. Chemoimmunotherapy. Cancer J United States. 2010;16:295-303.

23. Rijkers ESK, de Ruiter T, Baridi A, Veninga $H$, Hoek RM, Meyaard L. The inhibitory CD200R is differentially expressed on human and mouse $T$ and $B$ lymphocytes. Mol Immunol England. 2008;45:1126-35.
24. Lang S, Bruderek K, Kaspar C, Hoing B, Kanaan O, Dominas N, et al. Clinical relevance and suppressive capacity of human myeloid-derived suppressor cell subsets. Clin Cancer Res. United States. 2018. https://doi.org/10.1158/ 1078-0432.CCR-17-3726.

25. Yoyen-Ermis D, Ozturk-Atar K, Kursunel MA, Aydin C, Ozkazanc D, Gurbuz MU, et al. Tumor-induced myeloid cells are reduced by gemcitabine-loaded PAMAM dendrimers decorated with anti-Flt1 antibody. Mol Pharm United States. 2018;15:1526-33.

26. Mayanagi S, Kitago M, Sakurai T, Matsuda T, Fujita T, Higuchi H, et al. Phase pilot study of Wilms tumor gene 1 peptide-pulsed dendritic cell vaccination combined with gemcitabine in pancreatic cancer. Cancer Sci England. 2015; 106:397-406.

27. Maletzki C, Stier S, Gruenert U, Gock M, Ostwald C, Prall F, et al. Establishment, characterization and Chemosensitivity of three mismatch repair deficient cell lines from sporadic and inherited colorectal carcinomas. PLoS One. 2012;7. https://doi.org/10.1371/journal.pone.0052485.

28. Pelosof L, Yerram SR, Ahuja N, Delmas A, Danilova L, Herman JG, et al. CHFR silencing or microsatellite instability is associated with increased antitumor activity of docetaxel or gemcitabine in colorectal cancer. Int J cancer United States. 2014;134:596-605.

29. Ding ZC, Lu X, Yu M, Lemos H, Huang L, Chandler P, et al. Immunosuppressive myeloid cells induced by chemotherapy attenuate antitumor cd4 t-cell responses through the PD-1-PD-L1 axis. Cancer Res. 2014;74:3441-53.

30. Aricò E, Sestili P, Carpinelli G, Canese R, Cecchetti S, Schiavoni G, et al. Chemoimmunotherapy induces tumor regression in a mouse model of spontaneous mammary carcinogenesis. Oncotarget. 2016;7(37):59754-59765.

31. Bouffet $E$, Larouche $V$, Campbell BB, Merico D, De Borja R, Aronson M, et al. Immune checkpoint inhibition for hypermutant glioblastoma multiforme resulting from germline biallelic mismatch repair deficiency. J Clin Oncol. 2016:34:2206-11.

32. Shlien A, Campbell BB, De Borja R, Alexandrov LB, Merico D, Wedge D, et al. Combined hereditary and somatic mutations of replication error repair genes result in rapid onset of ultra-hypermutated cancers. Nat Genet. Nature Publishing Group. 2015;47:257-62 Available from: https://doi.org/10. 1038/ng.3202.

33. Castellucci E, He T, Goldstein DY, Halmos B, Chuy J. DNA Polymerase $\varepsilon$ Deficiency Leading to an Ultramutator Phenotype: A Novel Clinically Relevant Entity. Oncologist. 2017;22(5):497-502.

34. Domingo E, Freeman-Mills L, Rayner E, Glaire M, Briggs S, Vermeulen L, et al. Somatic POLE proofreading domain mutation, immune response, and prognosis in colorectal cancer: a retrospective, pooled biomarker study. Lancet Gastroenterol Hepatol. 2016;1:207-16.

35. Arbyn $M, X u L$, Simoens $C$, Martin-Hirsch PP. Prophylactic vaccination against human papillomaviruses to prevent cervical cancer and its precursors. Cochrane Database Syst Rev. England. 2018;5:CD009069.

36. Armstrong EP. Prophylaxis of cervical cancer and related cervical disease: a review of the cost-effectiveness of vaccination against oncogenic HPV types. J Manag Care Pharm United States. 2010;16:217-30.

37. Martin Lluesma S, Wolfer A, Harari A, Kandalaft LE. Cancer Vaccines in Ovarian Cancer: How Can We Improve? Biomedicines. 2016;4(2).

38. Westdorp H, Kolders S, Hoogerbrugge N, de Vries IJM, Jongmans MCJ, Schreibelt G. Immunotherapy holds the key to cancer treatment and prevention in constitutional mismatch repair deficiency (CMMRD) syndrome. Cancer Lett. Elsevier Ltd. 2017;403:159-64 Available from: https:// doi.org/10.1016/j.canlet.2017.06.018.

39. Amayiri N, Tabori U, Campbell B, Bakry D, Aronson M, Durno C, et al. High frequency of mismatch repair deficiency among pediatric high grade gliomas in Jordan. Int J Cancer. 2016;138:380-5.

40. Thaiss CA, Semmling V, Franken L, Wagner H, Kurts C. Chemokines: a new dendritic cell signal for T cell activation. Front Immunol. Switzerland. 2011;2:31.

41. Mailliard RB, Wankowicz-Kalinska A, Cai Q, Wesa A, Hilkens CM, Kapsenberg ML, et al. Alpha-type-1 polarized dendritic cells: a novel immunization tool with optimized CTL-inducing activity. Cancer Res. United States. 2004;64:5934-7.

42. Subbiah V, Murthy R, Hong DS, Prins RM, Hosing C, Hendricks K, et al. Cytokines produced by dendritic cells administered Intratumorally correlate with clinical outcome in patients with diverse cancers. Clin Cancer Res United States. 2018;24:3845-56.

43. Brown JM, Recht L, Strober S. The promise of targeting macrophages in Cancer therapy. Clin Cancer Res. United States. 2017;23:3241-50. 
44. González FE, Gleisner A, Falcón-Beas F, Osorio F, López MN, Salazar-Onfray F. Tumor cell lysates as immunogenic sources for cancer vaccine design. Hum Vaccin Immunother. 2014;10(11):3261-9.

45. Dutcher GMA, Bilen MA. Therapeutic vaccines for genitourinary malignancies. Vaccines Switzerland. 2018;6. https://doi.org/10.3390/vaccines6030055.

46. Konduri V, Li D, Halpert MM, Liang D, Liang Z, Chen Y, et al. Chemoimmunotherapy mediates durable cure of orthotopic KrasG12D/p53 -/-pancreatic ductal adenocarcinoma. Oncoimmunology. Taylor \& Francis. 2016;5:1-10 Available from: https://doi.org/10.1080/2162402X.2016.1213933.

47. Gogolak P, Rethi B, Hajas G, Rajnavolgyi E. Targeting dendritic cells for priming cellular immune responses. J Mol Recognit. England. 2003;16:299-317.

48. Coulie PG, Van Den Eynde BJ, Van Der Bruggen P, Boon T. Tumour antigens recognized by $T$ lymphocytes: at the core of cancer immunotherapy. Nat Rev Cancer. Nature Publishing Group. 2014;14:135-46 Available from: https://doi.org/10.1038/nrc3670

Ready to submit your research? Choose BMC and benefit from:

- fast, convenient online submission

- thorough peer review by experienced researchers in your field

- rapid publication on acceptance

- support for research data, including large and complex data types

- gold Open Access which fosters wider collaboration and increased citations

- maximum visibility for your research: over $100 \mathrm{M}$ website views per year

At BMC, research is always in progress. 